\title{
Dexamethasone Induces a Transient Relative Cardiomegaly in Neonatal Rats ${ }^{1}$
}

\author{
RAYMOND E. SICARD AND JOHN C. WERNER \\ Division of Pediatric Cardiology, Department of Pediatrics, Rhode Island Hospital and Division of Biology and \\ Medicine, Brown University, Providence, Rhode Island 02903
}

\begin{abstract}
Effects of s.c. administration of dexamethasone (1-25 $\mu \mathrm{g} /$ rat pup/d) during the first 5 d postpartum on survival rates, body weight, heart weight, heart-to-body weight ratios, and heart dimensions were determined. Dexamethasone decreased survival, body weight, and heart weight, but increased heart-to-body weight ratios and myocardial percentage of dry weight $(0.44$ to $0.52-1.06$ and 20 to $23 \%$, respectively; $p<0.05$ ) by 7 d postpartum. By 21 d postpartum, differences in absolute body weight and heart weight between control and experimental animals were reduced; however, myocardial percentage of dry weight and heart-to-body weight ratios were indistinguishable. Microscopic analysis of 7-d-old hearts disclosed that interventricular septum, left ventricular free wall thicknesses, and left ventricle chamber diameter were reduced $(0.93$ to 0.76 $0.85 \mathrm{~mm}, 1.19-1.34$ to $0.92-1.07 \mathrm{~mm}$, and $1.35-1.40$ to $0.89-1.23 \mathrm{~mm}$, respectively; $p<0.05$ ), whereas right ventricular free wall thickness was unaffected and right ventricle chamber diameter was increased $(0.29-0.31$ to 0.42 $0.46 \mathrm{~mm}$ ) by dexamethasone. Thus, dexamethasone reduced survival and retarded growth of neonatal rats. Retardation of heart growth was less severe, producing a transient relative cardiomegaly characterized by 1 ) increased myocardial percentage of dry weight, 2) increased left ventricular free wall-to-chamber ratio, and 3 ) retention of absolute right ventricular free wall thickness. This relative cardiomegaly appeared to be resolved by 21 d postpartum, as reflected in myocardial percentage of dry weight and heart-to-body weight ratios. These data suggest that this system might be a useful model for elucidating cellular and molecular mechanisms through which ventricular hypertrophy might arise in infants receiving dexamethasone therapy for bronchopulmonary dysplasia. (Pediatr Res 31: 359-363, 1992)
\end{abstract}

\section{Abbreviations}

BPD, bronchopulmonary dysplasia DEX, dexamethasone

IVS, interventricular septum

LVc, left ventricular chamber diameter

LVFW, left ventricular free wall

PP, postpartum

$R V c$, right ventricular chamber diameter

RVFW, right ventricular free wall

Management of premature infants with BPD can include treatment with steroids. Although amelioration of respiratory

Received June 13, 1991; accepted November 15, 1991.

Correspondence: John C. Werner, M.D., Division of Pediatric Cardiology, Rhode Island Hospital, Providence, RI 02903.

Preliminary results of this study appeared in abstract form in Pediatr Res 29:248A, 1991 status can be achieved (1-6), numerous side effects of steroid therapy have been noted. These include sepsis $(1,3,4)$, gastric ulcers (1), hyperglycemia, necrotizing enterocolitis, pneumothorax, osteomyelitis $(3,5)$, and impaired weight gain and growth (6). In addition, hypertension (1-3, 5, 7-9) and cardiac hypertrophy $(10,11)$ have been identified as sequelae. However, neither the clinical course nor natural history of apparent cardiac hypertrophy have been documented in detail. Nevertheless, a recent study suggests that left ventricular hypertrophy is induced within $3 \mathrm{wk}$ of the onset of steroid therapy (two daily doses of $250 \mu \mathrm{g} /$ $\mathrm{kg}$, tapered at 3-d intervals over $5 \mathrm{wk}$ ) and that this hypertrophy disappears over the ensuing 3 to 4 wk (12).

Enhancing the benefits and reducing the adverse sequelae attendant to steroid therapy of premature infants with BPD are immediate clinical objectives. Insights into how these objectives might be realized can be acquired through a combination of clinical investigations characterizing physiologic parameters of infants undergoing therapy and exploitation of animal models in which salient side effects paralleling those encountered clinically can be reproduced. This report describes a possible animal model in which myocardial effects of steroid administration during the neonatal period can be explored at the cellular and molecular levels.

\section{MATERIALS AND METHODS}

Animal husbandry. Adult Sprague-Dawley rats (CD strain) were acquired pregnant from Charles River Breeding Laboratories (Wilmington, MA) or were mated at the Central Research Facility at Rhode Island Hospital. Rats were housed individually in plastic cages and provided food and water ad libitum. At term, dams delivered their litters naturally and the number of pups in each litter was recorded. Subsequently, pups were allowed to nurse freely and remained with their mothers until 7 or $21 \mathrm{~d}$ PP.

Treatment protocol. Three distinct cohorts were generated: 1 ) normal controls, which received no treatment whatever; 2) experimental controls, which received $0.9 \%$ saline only; and 3 ) experimental animals, which received DEX (Elkins-Sinn, Inc., Cherry Hill, NJ). Normal control and experimental control groups were included in the experimental design to establish the effect of the manipulations used in this study on the characteristics to be evaluated. To identify the lowest DEX dose required to achieve maximal myocardial effects with good survival, a broad range of DEX concentrations were used. DEX concentrations of $1,5,12.5$, or $25 \mu \mathrm{g}$ per injection (corresponding to approximate initial dosages of $0.2,1,2.5$, and $5 \mathrm{mg} / \mathrm{kg} / \mathrm{d}$ ) were selected to approximate dosages used clinically (1 and $5 \mu \mathrm{g} /$ injection) and to provide greater assurance of achieving effects on the myocardium (12.5 and $25 \mu \mathrm{g}$ /injection). Saline or DEX was administered by s.c. injection (approximately $20 \mu \mathrm{L}$ ) into the cervical skin folds with each pup receiving four injections between $\mathrm{d} 1$ and $5 \mathrm{PP}$. No treatments were given after d 5 PP.

At $7 \mathrm{~d}$ PP, the number of animals remaining in each litter was 
recorded. In most cases, pups were removed from their cages and killed by decapitation while under anesthesia (sodium pentobarbital; Abbott Laboratories, No. Chicago, IL). Rats from the remaining litters representing the control, experimental control, and DEX [12.5 $\mu \mathrm{g}$ per injection $(2.5 \mathrm{mg} / \mathrm{kg} / \mathrm{d})$ ] groups were similarly killed at $21 \mathrm{~d}$ PP.

Parameters evaluated. Total body weight and heart wet weight were determined for animals in each group at $7 \mathrm{~d}$ PP. Several hearts from each group then were incubated overnight at $130^{\circ} \mathrm{C}$ for determination of myocardial percentage of dry weight. The remaining hearts were fixed in buffered formalin (Fisher Scientific, Medford, MA). Measurement of gross external dimensions were made before sending fixed samples to the histology laboratory for processing. Subsequent measurements of LVFW, LVc, IVS, RVFW, and RVc were made from stained (hematoxylin and eosin) paraffin sections using a compound microscope (at $400 \times$ ) equipped with an optical micrometer. Four to six measurements were made for every parameter assessed in each heart. Inasmuch as this investigation sought comparative effects among the various groups, rather than absolute myocardial dimensions, no correction was made for possible shrinkage due to formalin fixation.

Body weight, heart wet weight, and myocardial percentage of dry weight were also determined for animals killed at $21 \mathrm{~d}$ PP.

Heart weight to body weight ratios, myocardial percentage of dry weight, and ventricular wall to chamber ratios were derived directly from the above measurements. Myocardial volume and mass were approximated from linear dimensions obtained by direct measurement, as follows:

Volume $=4 / 3(\pi) \times($ subbasal width $/ 2)$

$\times$ (base to apical length/2)

$$
\text { Mass }=1.1 \times\left[(\mathrm{LVc}+\mathrm{IVS}+\mathrm{LVFW})^{3}-(\mathrm{LVc})^{3}\right]
$$

Although these equations have been validated for human hearts $(13,14)$, they might also provide a useful approximation of myocardial volume and mass for comparisons among the several groups created in this study.

Data analysis. The data are presented as the mean \pm 1 SEM for each parameter evaluated and are accompanied by designations of the sample size used in their derivation. Statistical analysis of data for each parameter consisted of one-way analysis of variance. Differences were considered significant at $p<0.05$.

Adherence to animal welfare guidelines. The procedures used in this investigation were reviewed and approved by the Animal Welfare Committee of Rhode Island Hospital. They are in conformity with current guidelines established by the National Institutes of Health.

\section{RESULTS}

Survival and growth. Litter sizes were comparable among all experimental groups, but tended to be slightly greater among control groups (Table 1). During the 1st wk of neonatal life, DEX reduced mean survival by up to $86 \%$. Reduction in survival appeared to be dose-related over the range of $1-25 \mu \mathrm{g}$ of DEX per injection.

Total body weight also was reduced by DEX; however, impairment of growth was not strictly dose-dependent. Nevertheless, higher doses of DEX retarded growth more than did lower doses (Table 1). For example, body weight was reduced relative to normal control rat pups by $70 \%$ when $25 \mu \mathrm{g}$ of DEX was administered with each injection, by $55 \%$ with 5 or $12.5 \mu \mathrm{g}$ of DEX per injection, and by $26 \%$ with $1 \mu \mathrm{g}$ of DEX per injection.

In addition, heart wet weight was reduced by DEX. However, this effect appeared to be biphasic, being more profound at intermediate DEX concentrations (Table 1). When DEX was administered at $5 \mu \mathrm{g}$ per injection, heart wet weight was reduced by $50 \%$ (from $70.5 \pm 1.5$ to $34.8 \pm 1.5 \mathrm{mg} ; p<0.005$ ), whereas
$25 \mu \mathrm{g}$ of DEX per injection reduced heart wet weight by only $32 \%$ (from $70.5 \pm 1.5$ to $48.1 \pm 4.2 \mathrm{mg} ; p<0.005$ ).

In contrast, the heart-to-body weight ratio was augmented with increasing DEX concentrations (Table 1). This increase was small $(13 \%)$ yet significant $(p<0.005)$ with low doses of DEX ( 1 and $5 \mu \mathrm{g}$ per injection), but substantial ( 2.3 times control) at high doses ( $25 \mu \mathrm{g}$ per injection).

Cardiac dimensions. The growth-retarding effects of DEX treatment were reflected in estimates of heart volume and mass (Table 2). (Methods for accurately measuring these parameters have been developed for clinical studies $(13,14)$. However, comparable methods have not been validated for hearts as small as those studied here. Nevertheless, estimates of heart volume and mass were performed using the above described methods to compare the effects within the diverse treatment groups but not to determine absolute measurements of heart volume or mass.)

DEX reduced both apparent heart mass and apparent heart volume (Table 2). In particular, the estimated heart volume was diminished by $18-33 \%$ (means reduced to $20.4-24.9 \mathrm{~mm}^{3}$ from $30.5 \mathrm{~mm}^{3}$ ), whereas the estimated heart mass was decreased by $31-62 \%$ (means reduced to $19.9-23.3 \mathrm{mg}$ from $52.6 \mathrm{mg}$ ). On the other hand, DEX had a biphasic effect on myocardial percentage of dry weight (Table 2). At $1 \mu \mathrm{g}$ of DEX per injection, myocardial percentage of dry weight was reduced by $10 \%$ (from $19.8 \pm 0.2$ to $17.8 \pm 0.4 \%$ ). In contrast, intermediate doses of $\operatorname{DEX}$ (5 and $12.5 \mu \mathrm{g}$ per injection) increased myocardial percentage of dry weight by $16.2-18.7 \%$ (from $19.8 \pm 0.2$ to $23.5 \pm$ 0.3 and $23.0 \pm 0.6 \%$, respectively) (Table 2 ).

The effects of DEX treatment were not uniformly expressed throughout the heart, however. In particular, DEX significantly $(p<0.05)$ reduced IVS, LVFW, and LVc relative to control and saline-treated groups (Table 3). Maximal reductions of $18 \%$ (from 0.93 to $0.76 \mathrm{~mm}$ ), $31 \%$ (from 1.34 to $0.92 \mathrm{~mm}$ ), and $36 \%$ (from 1.40 to $0.89 \mathrm{~mm}$ ) were observed for IVS, LVFW, and LVc, respectively. Reduction in LVFW and LVc, but not IVS, appeared to be dose-related. In contrast, DEX did not significantly alter RVFW or RVc. However, a trend toward a correlation between RVc and DEX concentration emerged, with marginally reduced $R V c$ at $1 \mu \mathrm{g}$ per injection $(0.25 \pm 0.02$ versus $0.31 \pm 0.05 \mathrm{~mm})$ and marginally expanded $\mathrm{RVc}$ at $12.5 \mu \mathrm{g}$ per injection $(0.46 \pm 0.01$ versus $0.31 \pm 0.05 \mathrm{~mm}$ ) (Table 3 ).

DEX reduced absolute left ventricular dimensions (sum of IVS + LVFW + LVc; Table 3) from a mean of $3.67 \mathrm{~mm}$ (controls) to means between 2.66 and $3.08 \mathrm{~mm}$ (DEX-treated groups). On the other hand, relative left ventricular myocardial thickness appeared to be increased at intermediate doses of DEX (5 and $12.5 \mu \mathrm{g}$ per injection). This appeared as a trend for ratios of myocardial wall (LVFW + IVS) to chamber (LVc) from DEXtreated rats to exceed those of control rats by up to $25 \%$ (means of 1.98-2.05 versus 1.68 and 1.62; Table 3 ). However, no significant differences as a consequence of DEX treatment were observed.

Posttreatment adjustment. Rats from several litters were allowed to develop for an additional $2 \mathrm{wk}$ (to $3 \mathrm{wk}$ PP) before being killed and evaluated. At this time, mean heart-to-body weight ratios of normal control, experimental control, and DEXtreated rats were comparable (between 0.40 and 0.43 ; Table 4). Moreover, mean myocardial percentage of dry weight also was comparable among all three groups (between 22 and 23\%; Table 4).

\section{DISCUSSION}

This investigation explored the suitability of the laboratory rat (Sprague-Dawley strain) as a possible model for investigating mechanisms through which DEX might induce transient myocardial hypertrophy in respirator-dependent infants undergoing treatment for BPD (12). An ideal model would reproduce all characteristics displayed by infants undergoing therapy. However, a model that paralleled (or mimicked) only the myocardial 
Table 1. Effects of DEX on survival and growth of neonatal rats during Ist wk PP*

\begin{tabular}{|c|c|c|c|c|c|}
\hline Treatment & $\begin{array}{c}\text { Litter } \\
\text { size } \\
\text { (pups/litter) } \\
\end{array}$ & $\begin{array}{c}\text { Survival } \\
(\%)\end{array}$ & $\begin{array}{c}\text { Body wt } \\
\text { (g) }\end{array}$ & $\begin{array}{l}\text { Heart wt } \\
(\mathrm{mg})\end{array}$ & $\begin{array}{c}\text { Heart-to-body } \\
\text { wt ratio } \\
(\times 100) \\
\end{array}$ \\
\hline None & $\begin{array}{c}12.5 \pm 0.7 \\
(n=6)\end{array}$ & $\begin{array}{c}95.8 \pm 2.8 \\
(n=6)\end{array}$ & $\begin{array}{r}14.9 \pm 0.2 \\
(n=57)\end{array}$ & $\begin{array}{r}70.5 \pm 1.5 \\
(n=41)\end{array}$ & $\begin{array}{r}0.46 \pm 0.01 \\
(n=41)\end{array}$ \\
\hline Saline & $\begin{array}{c}13.4 \pm 0.7 \\
(n=4)\end{array}$ & $\begin{array}{c}94.4 \pm 3.7 \\
(n=4)\end{array}$ & $\begin{array}{r}14.7 \pm 0.4 \\
(n=37)\end{array}$ & $\begin{array}{r}66.1 \pm 1.7 \\
(n=37)\end{array}$ & $\begin{array}{r}0.44 \pm 0.01 \\
(n=37)\end{array}$ \\
\hline \multicolumn{6}{|l|}{ DEX } \\
\hline $1 \mu \mathrm{g}$ & $\begin{array}{c}11.5 \pm 1.2 \\
(n=3)\end{array}$ & $\begin{array}{c}100.0 \pm 0.0 \\
(n=3)\end{array}$ & $\begin{array}{c}10.9 \pm 0.2 \dagger \\
(n=36)\end{array}$ & $\begin{array}{c}55.8 \pm 0.8 \dagger \\
(n=36)\end{array}$ & $\begin{array}{c}0.52 \pm 0.01 \dagger \\
\quad(n=36)\end{array}$ \\
\hline $5 \mu \mathrm{g}$ & $\begin{array}{c}11.4 \pm 1.8 \\
(n=5)\end{array}$ & $\begin{array}{c}82.2 \pm 12.6 \\
(n=5)\end{array}$ & $\begin{array}{c}6.7 \pm 0.1 \dagger \ddagger \\
(n=36)\end{array}$ & $\begin{array}{c}34.8 \pm 1.5 \dagger \ddagger \\
(n=36)\end{array}$ & $\begin{array}{c}0.53 \pm 0.02 \dagger \\
(n=36)\end{array}$ \\
\hline $12.5 \mu \mathrm{g}$ & $\begin{array}{c}11.2 \pm 1.2 \\
(n=5)\end{array}$ & $\begin{array}{c}72.5 \pm 18.8 \ddagger \\
(n=5)\end{array}$ & $\begin{array}{c}6.7 \pm 0.2 \dagger \\
(n=33)\end{array}$ & $\begin{array}{c}44.9 \pm 1.4 \dagger \ddagger \\
(n=30)\end{array}$ & $\begin{array}{c}0.67 \pm 0.02 \dagger \ddagger \\
(n=30)\end{array}$ \\
\hline $25 \mu \mathrm{g}$ & $\begin{array}{c}11.5 \pm 0.7 \\
(n=4)\end{array}$ & $\begin{array}{c}13.7 \pm 7.3+\ddagger \\
(n=4)\end{array}$ & $\begin{array}{l}4.5 \pm 0.2 \dagger \ddagger \\
(n=12)\end{array}$ & $\begin{array}{c}48.1 \pm 4.2 \dagger \\
(n=11)\end{array}$ & $\begin{array}{c}1.06 \pm 0.07+\ddagger \\
(n=11)\end{array}$ \\
\hline
\end{tabular}

* Results are mean $\pm 1 \mathrm{SEM} ; n$ represents either the number of litters studied (litter size and survival) or the number of pups used for measurements. Dosages represent quantities of DEX injected (s.c.) in $20 \mu \mathrm{L}$ saline per pup on each of four occasions between d 1 and 5 PP (total dose $=4 \times$ dose $)$

$\dagger p<0.005$ vs controls (no treatment or saline).

$\ddagger$ Significant effect $(p<0.025)$ of increasing DEX dose.

Table 2. DEX effects on estimated heart volume, estimated heart mass, and myocardial dry wt in neonatal rats during

\begin{tabular}{|c|c|c|c|}
\hline Treatment & $\begin{array}{l}\text { Volume } \\
\left(\mathrm{mm}^{3}\right)\end{array}$ & $\begin{array}{l}\text { Mass } \\
(\mathrm{mg})\end{array}$ & $\begin{array}{l}\text { Dry wt } \\
(\%)\end{array}$ \\
\hline None & $\begin{array}{r}30.5 \pm 0.2 \\
(n=11)\end{array}$ & $\begin{array}{c}52.6 \pm 8.0 \\
(n=5)\end{array}$ & $\begin{array}{r}19.8 \pm 0.2 \\
(n=30)\end{array}$ \\
\hline Saline & $\begin{array}{r}31.1 \pm 0.1 \\
(n=12)\end{array}$ & $\begin{array}{c}44.1 \pm 4.4 \\
(n=5)\end{array}$ & $\begin{array}{r}20.8 \pm 0.2 \\
(n=25)\end{array}$ \\
\hline \multicolumn{4}{|l|}{ DEX } \\
\hline $1 \mu \mathrm{g}$ & $\begin{array}{c}24.9 \pm 0.2 \dagger \\
(n=10)\end{array}$ & $\begin{array}{c}31.0 \pm 4.4 \dagger \\
(n=5)\end{array}$ & $\begin{array}{c}17.8 \pm 0.4 \dagger \\
(n=6)\end{array}$ \\
\hline $5 \mu \mathrm{g}$ & $\begin{array}{c}20.4 \pm 0.4 \dagger \ddagger \\
(n=10)\end{array}$ & $\begin{array}{c}23.3 \pm 2.1 \dagger \\
(n=10)\end{array}$ & $\begin{array}{c}23.5 \pm 0.3+4 \\
(n=25)\end{array}$ \\
\hline $12.5 \mu \mathrm{g}$ & $\begin{array}{c}21.5 \pm 0.1 \dagger \ddagger \\
(n=5)\end{array}$ & $\begin{array}{c}19.9 \pm 0.2 \dagger \\
(n=5)\end{array}$ & $\begin{array}{c}23.0 \pm 0.6 \ddagger \\
(n=30)\end{array}$ \\
\hline
\end{tabular}

* Results are mean $\pm 1 \mathrm{SEM} ; n$ represents the number of pups used for measurements. Dosages represent quantities of DEX injected (s.c.) in $20 \mu \mathrm{L}$ saline per pup on each of four occasions between d 1 and 5 PP (total dose $=4 \times$ dose)

$\dagger p<0.05 v s$ control (no treatment or saline).

$\ddagger p<0.01$ vs $1 \mu \mathrm{g}$ DEX.

changes described clinically could nevertheless provide a suitable tool for investigating the cellular and subcellular (molecular) mechanisms through which DEX produces these effects.

Dose-related increases in mortality and growth retardation were observed after administration of DEX to neonatal rat pups
(Table 1). Although the exact cause of death among DEX-treated pups was not determined, likely contributors are the metabolic, immunologic, and/or systemic dysfunctions induced by chronic high-dose glucocorticoid administration $(15,16)$. Nevertheless, good survival was achieved with DEX concentrations that paralleled those used by Werner et al. (12) in their clinical study. Between 80 and $100 \%$ survival was obtained with DEX doses of 1 and $5 \mu \mathrm{g}$ per injection per pup $(0.2$ and $1 \mathrm{mg} / \mathrm{kg} / \mathrm{d})$, which approximates the $0.5-\mathrm{mg} / \mathrm{kg} / \mathrm{d}$ DEX dose administered to respirator-dependent infants with BPD who developed hypertrophic cardiomyopathy.

Although growth retardation is not a consistent side effect of DEX therapy in infants (1-12), our observations are consistent with earlier reports of growth retardation in animals after administration of corticosteroids (17-19). This growth retardation has been attributed to suppression of DNA synthesis in some cases $(20,21)$. The number of rat pups in a litter also can influence subsequent growth (22). In particular, pups in large litters grow more slowly than pups from small litters. In this study, differences in litter size cannot account for the growth retardation observed (Table 1). First, control litters contained more pups, on average, than DEX-treated litters. Second, the greatest growth retardation was observed in litters containing the fewest survivors. Thus, the growth retardation observed appears to be linked to DEX treatment and the associated mortality but not to the number of pups in the litter.

Heart growth of neonatal rats also was decreased by DEX (Tables 1 and 2). This was reflected in reduced 1 ) heart wet weight, 2) estimated heart volume, and 3) estimated heart mass.

Table 3. Effects of DEX on dimensions and mass of neonatal rat hearts during 1 st wk PP*

\begin{tabular}{|c|c|c|c|c|c|c|}
\hline \multirow[b]{3}{*}{ Parameter } & \multicolumn{6}{|c|}{ Treatment } \\
\hline & \multirow[b]{2}{*}{ None } & \multirow[b]{2}{*}{ Saline } & \multicolumn{4}{|c|}{ Dexamethasone } \\
\hline & & & $1 \mu \mathrm{g}$ & $5 \mu \mathrm{g}$ & $12.5 \mu \mathrm{g}$ & $25 \mu \mathrm{g}$ \\
\hline IVS (mm) & $0.93 \pm 0.04$ & $0.93 \pm 0.01$ & $0.78 \pm 0.03 \uparrow$ & $0.76 \pm 0.02 \dagger$ & $0.85 \pm 0.03 \dagger$ & $0.78 \pm 0.1 \dagger$ \\
\hline LVFW (mm) & $1.34 \pm 0.08$ & $1.19 \pm 0.06$ & $1.07 \pm 0.04 \dagger$ & $1.07 \pm 0.08 \dagger$ & $0.92 \pm 0.05 \dagger$ & $0.95 \pm 0.1 \dagger$ \\
\hline $\mathrm{LVc}(\mathrm{mm})$ & $1.40 \pm 0.12$ & $1.35 \pm 0.12$ & $1.23 \pm 0.12$ & $0.97 \pm 0.10 \dagger$ & $0.89 \pm 0.07 \dagger$ & $0.96 \pm 0.4 \dagger$ \\
\hline $\mathrm{RVFW}(\mathrm{mm})$ & $0.48 \pm 0.12$ & $0.51 \pm 0.03$ & $0.46 \pm 0.01$ & $0.42 \pm 0.03$ & $0.43 \pm 0.02$ & ND \\
\hline $\mathrm{RVc}(\mathrm{mm})$ & $0.31 \pm 0.05$ & $0.29 \pm 0.02$ & $0.25 \pm 0.02$ & $0.33 \pm 0.02$ & $0.46 \pm 0.01$ & ND \\
\hline$(\mathrm{LVFW}+\mathrm{IVS}) / \mathrm{LVc}$ & $1.68 \pm 0.17$ & $1.62 \pm 0.16$ & $1.57 \pm 0.17$ & $1.98 \pm 0.27$ & $2.05 \pm 0.21$ & $1.80 \pm 0.16$ \\
\hline
\end{tabular}

* Results are mean \pm 1 SEM; $n$ for each group is 5. Dosages represent quantities of DEX injected (s.c.) in $20 \mu \mathrm{L}$ saline per pup on each of four occasions between $\mathrm{d} 1$ and $5 \mathrm{PP}$ (total dose $=4 \times$ dose). ND, not determined.

$\dagger p<0.05$ vs control (no treatment or saline). 
Table 4. Effects of short-term PP administration of DEX on body and heart mass of 21-d-old rats*

\begin{tabular}{|c|c|c|c|c|}
\hline Treatment & $\begin{array}{c}\text { Body wt } \\
\text { (g) }\end{array}$ & $\begin{array}{c}\text { Heart wt } \\
(\mathrm{mg})\end{array}$ & $\%$ Dry wt & $\begin{array}{c}\text { Heart-to-body } \\
\text { wt ratio } \\
(\times 100)\end{array}$ \\
\hline None & $\begin{array}{c}49.2 \pm 3.9 \\
(n=39)\end{array}$ & $\begin{array}{c}197.5 \pm 36.3 \\
(n=32)\end{array}$ & $\begin{array}{c}22.9 \pm 1.4 \\
(n=12)\end{array}$ & $\begin{array}{c}0.40 \pm 0.05 \\
(n=10)\end{array}$ \\
\hline Saline & $\begin{array}{c}43.1 \pm 3.2 \\
(n=10)\end{array}$ & $\begin{array}{c}183.1 \pm 14.1 \\
(n=10)\end{array}$ & $\begin{array}{c}22.1 \pm 1.0 \\
(n=5)\end{array}$ & $\begin{array}{c}0.43 \pm 0.04 \\
(n=10)\end{array}$ \\
\hline $\operatorname{DEX}(12.5 \mu \mathrm{g}$ per injection $)$ & $\begin{array}{c}37.3 \pm 5.0 \\
(n=9)\end{array}$ & $\begin{aligned} 150.9 & \pm 10.6 \\
(n & =9)\end{aligned}$ & $\begin{array}{c}22.7 \pm 0.7 \\
(n=4)\end{array}$ & $\begin{array}{c}0.41 \pm 0.04 \\
\quad(n=4)\end{array}$ \\
\hline
\end{tabular}

* Results are mean \pm 1 SEM.

Because heart volume and mass were estimated using methods that have not been validated for neonatal rat hearts, they cannot provide absolute measures of heart volume and mass. Nevertheless, their use as comparative indicators suggested that DEX reduced heart volume and mass relative to control rat hearts. Somewhat paradoxically, myocardial percentage of dry weight was increased by DEX (mean of up to $23.5 \%$ versus $19.8-20.8 \%$ for control groups; Table 2).

DEX did not suppress somatic growth and heart growth equally. In particular, heart growth seemed to be suppressed less than overall somatic growth. Moreover suppression of total somatic growth increased with increasing DEX dose, whereas suppression of heart growth was inversely correlated with DEX dose between 5 and $25 \mu \mathrm{g}$ per injection (Table 1). This yielded dose-related increases in heart-to-body weight ratios (Table 1) that were modest $(13 \%)$ at low doses of DEX but substantial $(2.3$ times control) at higher doses.

Because the hearts of treated rats were decreased in absolute terms but enlarged relative to total body size, a relative cardiomegaly was produced. This relative cardiomegaly contrasts with observations of other investigators who have reported cardiac hypertrophy after administration of corticosteroids. However, important differences exist between this study and those of other investigators. For example, Clark et al. (23) and Kurowski et al. (24) conducted their studies on adult rabbits and mature rats (45 d old), respectively. In addition, the reports of Alpert (10) and Werner et al. (12) identify effects in humans within a few weeks of corticosteroid administration. Thus, significant cardiac growth would not be expected to occur in these cases. In contrast, Hicks et al. (19) document absolute hypertrophy in a rapidly growing system (chick embryos). However, in that study only a single dose of corticosteroid was administered. Moreover, the substance used was one that could be metabolized by the recipient (deoxycorticosterone acetate). Consequently, the manner in which the organism's glucocorticoid milieu is altered can profoundly influence the results obtained. For example, manipulation of glucocorticoid levels by administration of ACTH or of native glucocorticoids (which can be metabolized) would be expected to produce short-lived physiologic effects. In contrast, the consequences of manipulating glucocorticoid levels through administration of DEX (a synthetic glucocorticoid) might be expected to be long-lived. These differences are consistent with the pharmacologic and physiologic properties of diverse steroids in different models (25).

The differential retardation of cardiac growth to total somatic growth suggests possible preferential sparing of heart muscle. This is consistent with the differential effects of DEX on several muscle types of adult rats observed by Kelly and Goldspink (26). These investigators noted that DEX $(2.5 \mathrm{mg} / \mathrm{kg} / \mathrm{d})$ led to atrophy of smooth and fast-twitch skeletal muscle, suppressed protein accumulation by slow-twitch skeletal muscle, and enhanced growth of cardiac muscle. Nevertheless, a positive effect of DEX on the hearts cannot be excluded. This possibility is raised by the increased percentage of dry weight of DEX-treated hearts (16-19\% above controls; Table 2). To what this might be attributed cannot be determined from the data presented. However, other studies suggest that total glycosaminoglycan, glycogen, lipid
(19), protein (26), and intracellular nonglycogen fibrillogranular substances (chemically undefined, 23) might be increased. Further studies are in progress to explore these possibilities.

Despite a reduction in overall mass, the hearts from DEXtreated rats appeared somewhat hypertrophic or hyperplastic. Three considerations suggest this interpretation. First, cardiac dry weight was increased (Table 2). This implies increased tissue mass and is consistent with hypertrophy (or hyperplasia). Second, RVFW was similar between control and DEX-treated animals (Table 3). Maintenance of absolute RVFW thickness in association with reduced total heart size suggests relative hypertrophy (or hyperplasia) of right ventricular myocardium. Third, the relative mass of the left ventricular walls (LVFW and IVS) appeared to be increased (Table 3). This is suggested by expansion of the ratio of left ventricular walls relative to the $\mathrm{LVc}$, which could reflect hypertrophy (or hyperplasia) of left ventricular myocardium. However, metabolic (e.g. RNA, protein, lipid, and glycogen content) and cellular (e.g. DNA content, cell numbers, and cell diameters) bases for these observations remain to be determined.

Similar increases in LVFW and IVS thicknesses relative to LVc were observed in human infants receiving DEX therapy for BPD by Werner et al. (12). However, absolute LVFW and IVS thicknesses are increased in infants receiving DEX therapy, whereas the increases reported here are only relative. Although complete reconciliation of contrasting observations in these studies is not possible, differences in the extent of ontogenic maturation and growth rate between infants and neonatal rats must be considered as contributory factors.

To determine whether the relative cardiomegaly induced was permanent or transient, rats from several litters were allowed to develop for an additional $2 \mathrm{wk}$ before being killed and evaluated. All surviving rats continued to grow, increasing total body weight and heart wet weight (compare Tables 1 and 4). However, rats that received DEX (12.5 $\mu \mathrm{g}$ per injection) apparently grew at a faster rate, inasmuch as their body weights were now $76 \%$ of control ( $37.3 \pm 5.0$ versus $49.2 \pm 3.9 \mathrm{~g}$; Table 4$)$ as compared with being only $45 \%$ of control at $7 \mathrm{~d}$ PP $(6.7 \pm 0.2$ versus 14.9 $\pm 0.2 \mathrm{~g}$; Table 1). Similarly, the difference in heart wet weight between DEX-treated and control animals was reduced, although not to as great a degree ( $76 \%$ of control at 3 wk PP versus $64 \%$ of control at $7 \mathrm{~d}$ PP). Moreover, no differences in myocardial percentage of dry weight or in heart-to-body weight ratio could be found between control and DEX-treated rats. These observations suggest that the relative cardiomegaly induced by DEX treatment was transient. The transient nature of this apparent relative cardiomegaly parallels the transient hypertrophic cardiomyopathy in respirator-dependent human infants receiving high-dose DEX therapy for BPD reported by Werner et al. (12).

Summary and conclusions. High-dose DEX therapy is frequently used in the management of respirator-dependent infants with BPD. This therapy produces numerous adverse side effects (1-6), including a recently documented transient hypertrophic cardiomyopathy (12). Although the clinical and pathophysiologic implications of these cardiovascular alterations are not yet characterized, a fuller appreciation of the role of DEX in the etiology of the ventricular hypertrophy encountered is warranted. The 
development of an animal model that reproduces or mimics the salient features of this ventricular hypertrophy can provide a powerful tool for achieving this objective.

Treatment of neonatal rats with DEX retarded total somatic growth and heart growth. Because somatic growth suppression correlated positively and heart growth suppression correlated negatively with increasing DEX dosage, heart-to-body weight ratios were increased by DEX treatment. Moreover, although absolute heart mass was reduced by DEX, myocardial percentage of dry weight was increased. Thus, DEX induced a transient relative cardiomegaly as determined by 1 ) increased heart-tobody weight ratio and 2) increased myocardial percentage of dry weight. In addition, this relative cardiomegaly was achieved at DEX concentrations similar to those used therapeutically that induce hypertrophic cardiomyopathy. Moreover, two major characteristics of this relative cardiomegaly parallel features of the hypertrophic cardiomyopathy seen clinically: 1 ) expansion of LVFW and IVS relative to LVc, and 2) resolution to apparent cardiac normalcy (reflected in heart-to-body weight ratio and myocardial percentage of dry weight in this study and in pretreatment dimensions of myocardial walls in the clinical study).

The results of this investigation suggest that the model described here can mimic certain, but not all, characteristics of a transient hypertrophic cardiomyopathy induced in respiratordependent infants receiving high-dose DEX therapy for BPD. Consequently this model might be exploited to provide additional insights into the cellular and subcellular mechanisms through which DEX therapy for BPD induces this hypertrophic cardiomyopathy in infants.

\section{REFERENCES}

1. Kramer LI, Hultzen C 1978 The role of steroids in early bronchopulmonary dysplasia (BPD). Pediatr Res 12:564A(abstr)

2. Grylack LJ, Scanlon KB, Scanlon LW 1979 Corticosteroid treatment of fourteen newborns with bronchopulmonary dysplasia. Clin Res 27:819A(abstr)

3. Pomerance JJ, Puri AR 1980 Treatment of neonatal bronchopulmonary dysplasia with steroids. Pediatr Res 14:649A(abstr)

4. Pomerance JJ, Puri AR 1982 Treatment of severe bronchopulmonary dysplasia with steroids. Pediatr Res 16:359A(abstr)

5. Mammel MC, Green TP. Johnson DE, Thompson TR 1983 Controlled trial of dexamethasone therapy in infants with bronchopulmonary dysplasia. Lancet 1:1356-1358
6. Harkavy KL, Scanlon JW. Chowdhry PK, Grylack LJ 1989 Dexamethasone therapy for chronic lung disease in ventilator-and oxygen-dependent infants: a controlled trial. J Pediatr 115:979 983

7. Avery GB, Fletcher AB, Kaplan M, Brudno DS 1985 Controlled trial of dexamethasone therapy in respirator-dependent infants with bronchopulmonary dysplasia. Pediatrics 75:106-111

8. Singhad N, McMillan DD, Stephura DK 1990 Effect of ACTH and dexamethasone (DXM) on infants with bronchopulmonary dysplasic (BPD). Pediatr Res 27:226A(abstr)

9. Fish WH 1990 Hypertension associated with dexamethasone treatment of chronic lung disease in infants. Pediatr Res 27:302A(abstr)

10. Alpert BS 1984 Steroid-induced hypertrophic cardiomyopathy in an infant Pediatr Cardiol 5:117-118

11. Schuster JD Gidding SS 1990 Possible relationship of acquired hypertrophic cardionyopathy to corticosteroid therapy in premature infants with bronchopulmonary dysplasia. Pediatr Res 27:237A(abstr)

12. Werner JC, Sicard RE, Hansen TWR, Solomon E, Cowett RM, Oh W 1992 Hypertrophic cardiomyopathy with dexamethasone therapy for bronchopulmonary dysplasia (BPD). J Pediatr 89:286-291

13. Katz AM 1977 Physiology of the Heart. Raven Press, New York

14. Devereux RB, Reichek N 1977 Echocardiographic determinations of left ventricular mass in man: anatomical validation of the method. Circ Res 55:613-618

15. Fitzhardinge PM, Eisen A, Lejtenyi C, Metrakos K, Ramsay M 1974 Sequelae of early steroid administration to the newborn infant. Pediatrics 53:877-883

16. Axelrod L 1989 Side effects of glucocorticoid therapy. In: Schleimer RP Claman HN, Oronsky A (eds) Anti-inflammatory Steroid Action: Basic and Clinical Aspects. Academic Press, New York, pp 377-408

17. Shapiro $\mathrm{S} 1968$ Some physiological, biochemical, and behavioral consequences of neonatal hormone administration: cortisol and thyroxine. Gen Comp Endocrinol 10:214-228

18. Loeb JN 1976 Corticosteroids and growth. N Engl J Med 295:547-552

19. Hicks DC Lee JA, Kilgore BS, Burnett CR, Schewedie HK, Hughes ER, Elders MJ 1982 Glucocorticoid effects on the embryonic chick heart. I. Glucocorticoid enlargement of the heart. Ann Clin Lab Sci 12:477 -483

20. Henderson IC, Fischel RE, Loeb JN 1971 Suppression of liver DNA synthesis by cortisone. Endocrinology 88:1471-1476

21. Loeb JN, Yeung LL 1973 Effects of cortisone on thymidine incorporation by various nonlymphoid tissues of the weanling rat. Proc Soc Exp Biol Med 143:503-507

22. Cha C-JM, Oh W 1986 Growth and fatty acid metabolism in experimental intrauterine growth retardation: effect of postnatal nutrition. J Nutr 116:1080-1087

23. Clark AF. Tandler B, Vignos $\mathrm{J}_{\Gamma}$ PJ 1982 Glucocorticoid-induced alterations in the rabbit heart. Lab Invest 47:603-610

24. Kurowski TT, Chatterton Jr RT, Hickson RC 1984 Glucocorticoid-induced cardiac hypertrophy: additive effect of exercise. J Appl Physiol 57:514-519

25. Szefler SJ 1989 General pharmacology of glucocorticoids. In: Schleimer RP Claman HN, Oronsky A (eds) Anti-inflammatory Steroid Action: Basic and Clinical Aspects. Academic Press, New York, pp 353-376

26. Kelly FJ, Goldspink DF 1982 The differing responses of four muscle types to dexamethasone treatment in the rat. Biochem J 208:147-15 